\title{
PELATIHAN KOMUNIKASI EFEKTIF MEDIA PEMBELAJARAN GOOGLE CLASSROOM BAGI GURU MAN 2 MODEL PEKANBARU
}

\author{
Fitria Mayasari*, Desliana Dwita, Jupendri, Jayus, Nazhifah, \\ Khusnul Hanafi, Nolly Medya Putra \\ Prodi Ilmu Komunikasi, Fakultas Ilmu Komunikasi \\ Universitas Muhammadiyah Riau \\ email: : fitria.mayasari@umri.ac.id
}

\begin{abstract}
In today's digital era, teaching staff have many choices of interactive learning media that can support the learning process. One application that can help teachers realize effective communication between students and teachers is google classroom. The Google Classroom is a mixed learning platform that is intended for every educational scope that is intended to find a way out of the difficulties in making, sharing and classifying each paperless assignment. For this reason, there is a need for knowledge and skills about how effective communication can be done through innovative learning media based on Blended Learning (Google Classroom), so that the quality of teaching can be better. Therefore, dedication activities are carried out in MAN 2 Model on "Effective Communication Training through Blended-Learning (Google Classroom) Innovative Learning Media for Teachers in MAN 2 Model Pekanbaru". The material presented included effective communication, innovative learning media based on Blended Learning, and the use of google classroom as a medium to support innovative and communicative learning.
\end{abstract}

Keywords: Effective communication, google classroom, MAN 2 Model Pekanbaru

\begin{abstract}
Abstrak
Di era digital saat ini, tenaga pengajar memiliki banyak pilihan media pembelajaran interaktif yang dapat menunjang proses pembelajaran. Salah satu aplikasi yang dapat membantu para guru mewujudkan komunikasi yang efektif antara siswa dan guru adalah google classroom. Google Classroom (Ruang Kelas Google) adalah suatu serambi pembelajaran campuran yang diperuntukkan terhadap setiap ruang lingkup pendidikan yang dimaksudkan untuk menemukan jalan keluar atas kesulitan dalam membuat, membagikan dan menggolong-golongkan setiap penugasan tanpa kertas. Untuk itu perlu adanya pengetahuan dan keterampilan tentang bagaimana komunikasi efektif dapat dilakukan melalui media pembelajaran inovatif berbasis Blended Learning (Google Classroom), sehingga kualitas pengajaran dapat lebih baik. Oleh karena itu dilakukan kegiatan pengabdian di MAN 2 Model mengenai "Pelatihan Komunikasi Efektif Melalui Media Pembelajaran Inovatif Berbasis Blended-Learning (Google Classroom) Bagi Guru-Guru di MAN 2 Model Pekanbaru”. Materi yang disampaikan meliputi komunikasi efektif, media pembelajaran inovatif berbasis Blended Learning, serta penggunaan google classroom sebagai media penunjang pembelajaran yang inovatif dan komunikatif.
\end{abstract}

Kata kunci : Komunikasi efektif, google classroom, MAN 2 Model Pekanbaru

\section{PENDAHULUAN}

Pengajaran yang efektif dapat ditinjau berdasarkan kualitas hasil pembelajaran siswa. Baik berupa hasil pemikiran yang dapat disampaikan kembali oleh siswa melalui pembicaraan langsung maupun tertulis. Mengelola kelas dan memecahkan konflik dalam pembelajaran secara konstruktif membutuhkan keterampilan komunikasi yang baik. Komunikasi yang efektif antara guru dan murid merupakan faktor 
penting terciptanya hal tersebut. Selain keterampilan berbicara secara verbal, penggunaan media pembelajaran dapat membantu terciptanya komunikasi yang efektif dalam kegiatan belajar mengajar. Perkembangan teknologi informasi dan komunikasi saat ini telah memunculkan beragam jenis media pembelajaran interaktif, yang dapat dimanfaatkan oleh para guru demi menunjang kegiatan pembelajaran.

Untuk dapat melaksanakan tugasnya secara profesional, seorang guru dapat memahami dan memiliki keterampilan yang memadai dalam mengembangkan berbagai model pembelajaran yang efektif, kreatif dan menyenangkan. Undang-undang Sistem Pendidikan Nasional No. 20 Tahun 2003 menyatakan pembelajaran adalah proses interaksi peserta didik dengan pendidik dan sumber belajar pada suatu lingkungan belajar. Pembelajaran sebagai proses belajar yang dibangun oleh guru untuk mengembangkan kreativitas berpikir yang dapat meningkatkan kemampuan berpikir siswa, serta dapat meningkatkan kemampuan mengkonstruksi pengetahuan baru sebagai upaya meningkatkan penguasaan yang baik terhadap materi pelajaran.

Fenomena meningkatnya akses internet oleh kalangan muda saat ini yang biasa disebut sebagai digital native sedikit banyak mempengaruhi aktifitas dan pola belajar di kalangan siswa-siswi sekolah menengah. Baik itu secara positif maupun negatif. Berdasarkan temuan riset Kominfo dan UNICEF mengenai penggunaan internet di kalangan anak-anak dan remaja di Indonesia pada tahun 2014 seperti dilansir dari situs kominfo.go.id, sebagian besar anak-anak dan remaja di Indonesia sekarang sudah mengakses internet secara teratur dalam berbagai kegiatan. Sebagian besar responden $(80$ $\%$ ) menggunakan internet untuk mencari data dan informasi, khususnya untuk tugas-tugas sekolah, atau untuk bertemu teman online $(70 \%)$ melalui platform media sosial . Kelompok besar lain mengklik melalui musik $(65 \%)$ atau video $(39 \%)$ situs.

Dari hasil riset tersebut juga ditemukan bahwa hampir sembilan dari sepuluh anak-anak (89\%) berkomunikasi secara online dengan teman-teman sementara kelompok-kelompok yang lebih kecil juga berinteraksi dengan keluarga mereka (56\%) atau guru mereka (35\%) melalui internet, dan topik yang paling dibicarakan berhubungan dengan kegiatan sekolah. Maraknya penggunaan smartphone juga memainkan peran yang penting dalam peningkatan akses internet oleh kalangan remaja.

Meningkatnya akses internet dikalangan siswa ibarat pisau bermata dua. Di satu sisi perkembangan media sosial dan media hiburan lain yang berbasis internet mampu mengalihkan perhatian siswa dalam proses belajar mengajar sehingga komunikasi yang efektif sulit untuk tercapai. Di satu sisi kemunculan beragam aplikasi pencarian informasi dan media pembelajaran mampu menunjang proses kegiatan belajar mengajar menjadi lebih efektif. Cara pengajaran yang monoton dan konvensional dianggap kurang menarik dan tidak efektif dalam menarik minat belajar siswa. Model pembelajaran yang interaktif dapat membangkitkan motivasi, minat atau gairah belajar siswa, serta dapat memberikan kesempatan bagi siswa untuk memberikan tanggapannya terhadap materi yang disampaikan.

Kata "media" secara umum dapat diartikan sebagai alat/perantara yang digunakan untuk menyalurkan suatu objek dari satu tempat/pihak ke tempat/pihak yang lain.

Kaitannya dengan kegiatan belajar mengajar di kelas, media 
pembelajaran adalah alat bantu yang dapat menjabarkan pesan atau informasi dari guru ke siswa yang bertujuan mempermudah proses pembelajaran. Dengan dimanfaatkannya media pembelajaran, diharapkan pikiran, perasaan, perhatian dan minat siswa dapat terangsang sehingga pada akhirnya siswa dapat menerima dan memahami informasi (materi) dari guru dengan baik.

Blended Learning adalah metode pembelajaran yang menggabungkan antara metode konvensional /tatap muka dengan pembelajaran online. Pembelajaran berbasis teknologi informasi, akan memberikan pengalaman terbaik bagi guru dan siswa saat melakukan kegiatan belajar mengajar. Model pembelajaran seperti ini merupakan salah satu model pembelajaran inovatif yang mendukung adanya efisiensi waktu maupun kampanye paperless.

Salah satu aplikasi yang dapat membantu para guru mewujudkan komunikasi yang efektif antara siswa dan guru adalah google classroom. Google Classroom (atau dalam bahasa Indonesia yaitu Ruang Kelas Google) adalah suatu serambi pembelajaran campuran yang diperuntukkan terhadap setiap ruang lingkup pendidikan yang dimaksudkan untuk menemukan jalan keluar atas kesulitan dalam membuat, membagikan dan menggolonggolongkan setiap penugasan tanpa kertas. Perangkat lunak ini telah diperkenalkan sebagai keistimewaan Google Apps for Education sejak 12 Agustus 2014.

Selain hal tersebut, tentu penggunaan media pembelajaran google classroom dapat menjadi sarana komunikasi efektif antara guru dan siswa dengan memanfaatkan berbagai fitur komunikasi yang ada pada aplikasi tersebut. Untuk itu perlu adanya pengetahuan dan keterampilan tentang bagaimana komunikasi efektif dapat dilakukan melalui media pembelajaran inovatif berbasis Blended Learning (Google Classroom), sehingga kualitas pengajaran dapat lebih baik.

\section{METODE PENGABDIAN}

Dalam kegiatan pengabdian, tim pelaksana melakukan 4 (empat) metode pelaksanaan program pengabdian ini yakni Pelatihan, Diskusi, Bimbingan dan Evaluasi.

Pelatihan dimaknai sebagai proses pemberian pengetahuan dan pemahaman kepada para Guru mengenai komunikasi efektif melalui media pembelajaran inovatif berbasis blended learning. Diskusi dimaknai sebagai upaya pembentukan pengembangan kreatif dan inovatif para Guru dalam memanfaatkan media pembelajaran berbasis blended learning. Bimbingan dimaknai sebagai kegiatan pembentukan dan pembinaan kepada para Guru, sehingga memiliki keterampilan dalam menggunakan media pembelajaran inovatif berbasis blended learning (google classroom). Evaluasi dimaknai sebagai pengawasan dan penilaian atas pelaksanaan penggunaan media pembelajaran inovatif berbasis blended learning (google classroom).

\section{HASIL DAN PEMBAHASAN}

Kegiatan pelatihan Pelatihan Komunikasi Efektif Melalui Media Pembelajaran Inovatif Berbasis Blended Learning (Google Classroom) Bagi Guru-Guru di MAN 2 Model Pekanbaru membuka wawasan para guru mengenai pentingnya komunikasi efektif dalam proses pembelajaran, serta memiliki keterampilan dalam menciptakan komunikasi efektif dalam proses pembelajaran melalui penggunaan Google Classroom.

Kegiatan dilakukan di Aula Mini MAN 2 Model Pekanbaru. Dihadiri oleh Waka Humas serta para guru di MAN 2 Model Pekanbaru. Acara dilaksanakan 
pada hari Sabtu tanggal 15 Desember 2018 mulai pukul 10.00 WIB hingga pukul 12.00 WIB. Pemateri terdiri dari Nazhifah,S.I.Kom,M.I.Kom, Khusnul Hanafi, S.I.Kom, M.Soc.Sc, serta Fitria Mayasari, S.I.Kom, MA. Sedangkan pembawa acara dilakukan oleh Desliana Dwita, S.IP, M.I.Kom.

Sebelum penjelasan materi dimulai, acara dibuka oleh pembawa acara yang kemudian dilanjutkan penyampaian kata sambutan oleh Ketua Pelaksana kegiatan pengabdian dan Waka Humas MAN 2 Model Pekanbaru. Setelah sambutan dari Waka Humas MAN 2 Model Pekanbaru, acara dilanjutkan dengan penyampaian materi dimulai tentang materi Komunikasi Efektif yang disampaikan oleh Nazhifah,S.I.Kom,M.I.Kom. Materi tentang Komunikasi Efektif dimulai dengan penyampaian tentang pengertian komunikasi efektif. Komunikasi efektif adalah komunikasi yang pada prosesnya dapat menghasilkan persepsi, perilaku dan pemahaman yang berubah menjadi sama antara komunikator dan komunikan. Berkomunikasi efektif berarti bahwa komunikator dan komunikan sama-sama memiliki pengertian yang sama tentang suatu pesan, sesuai dengan harapan komunikator.

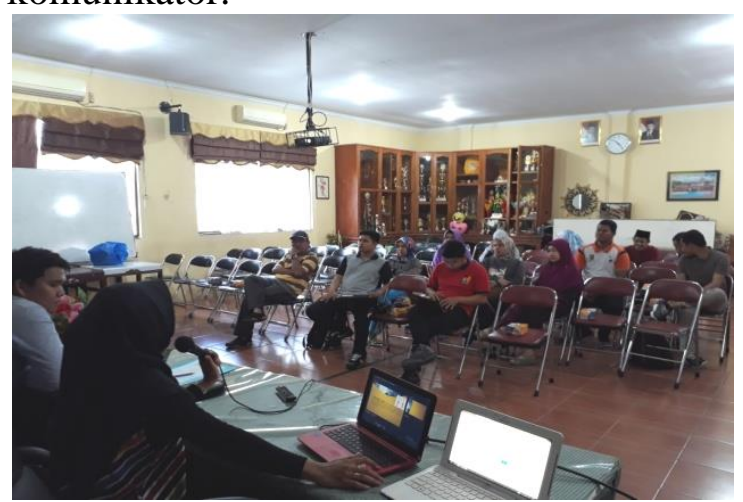

Gambar 1. Materi tentang Komunikasi Efektif

Setelah materi mengenai komunikasi efektif, acara dilanjutkan dengan penyampaian materi mengenai pengenalan google classroom yang disampaikan oleh Khusnul Hanafi,
S.I.Kom, M.Soc.Sc. Sebelum penyampaian materi, pemateri bertanya kepada peserta pelatihan apakah peserta sudah memiliki akun google classroom atau sudah pernah menggunakan google classroom.

Mayoritas peserta pelatihan belum memiliki atau menggunakan google classroom. Pemateri kemudian membuka materi dengan memberi penjelasan mengenai apa itu google classroom dan bagaimana membuat akun google classroom dan menggunakan fitur-fitur yang ada di google classroom.

Google Classroom (Ruang Kelas Google) adalah suatu serambi pembelajaran campuran yang diperuntukkan terhadap setiap ruang lingkup pendidikan yang dimaksudkan untuk menemukan jalan keluar atas kesulitan dalam membuat, membagikan dan menggolong-golongkan setiap penugasan tanpa kertas. Perangkat lunak ini telah diperkenalkan sebagai keistimewaan Google Apps for Education sejak 12 Agustus 2014.

Untuk dapat menggunakan google classroom, pengguna harus memiliki akun gmail atau akun google terlebih dahulu. Kemudian membuka lama classroom.google dan membuat kelas sesuai dengan mata pelajaran yang diampu.

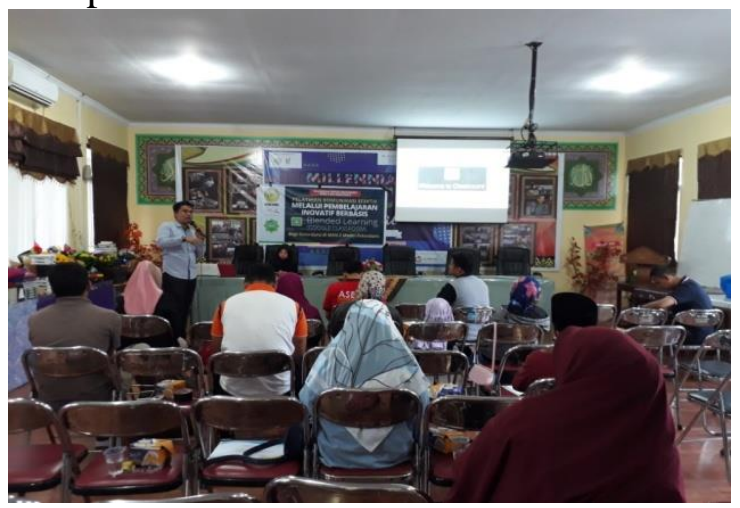

Gambar 2. Penyampaian Materi oleh Khusnul Hanafi S.I.Kom, M.Soc.Sc

Materi ketiga dalam pelatihan komunikasi efektif melalui Google 
Classroom bagi Guru-Guru di MAN 2 Model Pekanbaru adalah mengenai media pembelajaran inovatif dan komunikatif melalui google classroom. Google classroom memudahkan siswa dan guru agar tetap terhubung, baik di dalam maupun di luar kelas.

Google classroom adalah platform pembelajaran campuran yang dikembangkan oleh google untuk menyederhanakan pembuatan dan pembuatan tugas, menghemat waktu, dan meningkatkan komunikasi dengan siswa. Dengan maksud mempermudah guru dalam mengelola kelas.

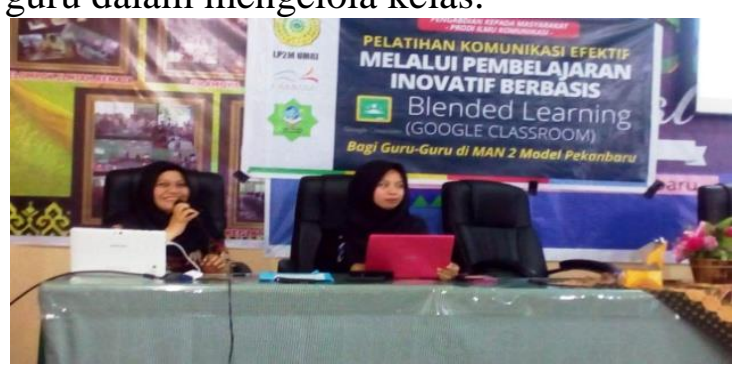

Gambar 3. Penyampaian Materi oleh

Fitria Mayasari,S.I.Kom,M.A

Setelah penyampaian oleh para pemateri, sesi tanya jawab dan diskusi dibuka. Peserta pelatihan atas nama Delfi menyampaikan apresiasi atas penyelenggaraan pelatihan tersebut dengan menyatakan bahwa materi mengenai komunikasi efektif melalui Google Classroom merupakan pelatihan yang sangat dibutuhkan oeh tenaga pengajar di tengah perkembangan saat ini.

Dikarenakan memang belum banyak tenaga pengajar yang memahami penggunaan google classroom dalam kegiatan belajar-mengajar. Peserta selanjutnya atas nama Dermawan menanyakan bagaimana penggunaan classroom ketika ada beberapa hal yang kurang memungkinkan dalam proses pembelajaran.

Seperti jam belajar full day serta peraturan di sekolah yang tidak mengizinkan para siswa untuk menggunakan gadget ketika proses belajar-mengajar berlangsung. Setelah seluruh pertanyaan dari peserta pelatihan selesai dijawab oleh pemateri, kegiatan tersebut diakhiri dengan foto bersama dengan seluruh peserta kegiatan pelatihan komunikasi efektif melalui Google Classroom di MAN 2 Model Pekanbaru.

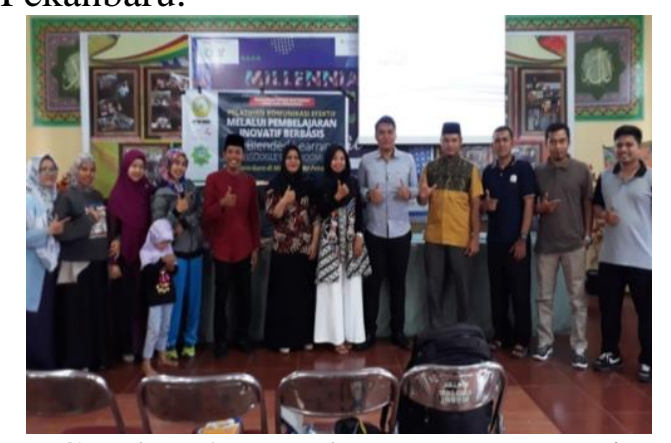

Gambar 4. Foto bersama pemateri dengan peserta

\section{SIMPULAN}

Kemampuan berkomunikasi efektif merupakan hal yang harus dimiliki tenaga pengajar dalam proses pembelajaran di kelas. Saat ini perkembangan teknologi memungkinkan hadirnya beragam model dan media pembelajaran yang dapat mendukung terciptanya komunikasi yang efektif dalam proses pembelajaran di kelas.

Salah satunya adalah model pembelajaran blended learning dengan menggunakan ragam media pembelajaran yang ada saat ini. Untuk dapat melaksanakan tugasnya secara profesional, seorang guru dapat memahami dan memiliki keterampilan yang memadai dalam mengembangkan berbagai model pembelajaran yang efektif, kreatif dan menyenangkan.

\section{UCAPAN TERIMAKASIH}

Ucapan terima kasih disampaikan kepada:

- Lembaga Penelitian dan Pengabdian Masyarakat (LPPM) Universitas Muhammadiyah Riau (UMRI) yang telah memberikan dukungan berupa biaya dan motivasi. 
- Fakultas Ilmu Komunikasi Universitas Muhammadiyah Riau yang telah memberi dukungan agar terselenggaranya kegiatan pengabdian kepada masyarakat ini.

- Kepala Sekolah, Waka Humas, para guru, di lingkungan MAN 2 Model Pekanbaru

- Seluruh peserta pelatihan, yaitu para guru di MAN 2 Model Pekanbaru yang antusias dalam mengikuti kegiatan ini.

\section{DAFTAR PUSTAKA}

[1.] Arsyad, A., 2013, Media Pembelajaran. Jakarta: PT. Raja Grafindo Persada.

[2.] Cangara, Hafied. 2012. Pengantar Ilmu Komunikasi (Edisi 2). Jakarta: Rajawali Pers

[3.] Komara E., 2014. Belajar dan Pembelajaran Interaktif, Bandung: PT Refika Aditama

[4.] Kuntarto, Eko dan Asyhar, Rayandra. 2016. Pengembangan Model Pembelajaran Blended Learning Pada Aspek Learning Design Dengan Platform Media Sosial Online Sebagai Pendukung Perkuliahan Mahasiswa. Artikel Jurnal Universitas Jambi. Diakses melalui http://repository.unja.ac.id/626/ tanggal 5 Desember 2018

[5.] Kustandi, C. dan Sutjipto, B., 2011. Media Pembelajaran: Manual dan Digital. Bogor: Ghalia Indonesia

[6.] McPheat, Sean. 2010. Effective Comunication Skills.

Swedia:MTD Training \& Ventus Publishing

[7.] Unicef.org. 2014. Studi Terakhir:
Kebanyakan Anak Indonesia sudah online, namun masih banyak yang tidak menyadari potensi resikonya. Diakses dari https://www.unicef.org/indonesia/ id/media_22169.html tanggal 14 Juli 2018 